\title{
Optimizing Character Education for Adolescents Plagued by Free Intercourse
}

\author{
Talahi brendan, Nadzli Rozidu \\ Faculty of Education, University of Malaya, Malaysia \\ Received: January 15, 2021 \\ Revised: February 27, 2021 \\ Accepted: March 6, 2021

\begin{abstract}
Adolescent character education is extremely important. Promiscuity, rampant rates of aggression against children and youth, robberies against peers, juvenile theft, cheating behaviors, substance addiction, pornography, and the misuse of others' property have all been global issues that have yet to be fully addressed. The article explains the philosophy of adolescent character education, the function of adolescent character education, the urgency of adolescent character education, the factors that affect character education, and the enhancement of adolescent character education for adolescent promiscuity. Attitudes, emotions, will, values, and behaviors are all ingredients in the definition of character education for teenagers.
\end{abstract}

Keywords: Adolescent character, Promiscuity \& Attitudes

\section{Introduction}

The psychophysics defines the individual's particular adaptations to the world, and character is the organization inherent in the human. So, character is a special way of thinking and acting that allows people to live and work together in the family, society, country, and state. The aim of national education is to help students reach their full potential in terms of intellect, attitude, and morality.

Character education is a type of character education that includes elements of experience, emotions, and behavior (Dodds, 2016; Richardson et al., 2009; Vaccarezza \& Niccoli, 2019). Character teaching would be ineffective without these three elements. A kid would be emotionally intelligent if character instruction is applied in a consistent and continuous manner. This relational maturity is a crucial component in educating children for the future, since it can make it simpler and more competitive for them to face all of life's obstacles, including the difficulty of academic achievement (Wagner, 2010; Jensen, 2009).

Character schooling, which is concerned with students' moral formation and behavior, is accomplished by instilling strong faith and traditional values. The integrity must be instilled in all subjects with the same fervor. As a result, a set of key values must be chosen as a starting point for planting other values. Associational delinquency is the most noticeable type of adolescent delinquency (Short, 1957). There are already a lot of teens who are stuck in poor marriages. From the usage of illicit substances and unrestricted women. It is relatively straightforward to drag teens into a poor relationship and they are quickly swayed by unpleasant items that provide false comfort. Teenagers, and even their mothers, face a significant stigma as a part of this promiscuity.

In coping with adolescent delinquency, the following actions must be taken: Prevention or preventive intervention is an operation that is carried out routinely, organized, and directed in order to deter such delinquency from occurring. This initiative is taken after all preventative measures have been taken which is considered appropriate to improve the actions of students who have violated the rules by offering re-education. This schooling is replicated with the help of specialists in the area who have unique and individual advice. Curative intervention is an 
attempt to predict the signs of delinquency so order to prevent it from spreading and causing harm to the group.

There are many psychological and sociological factors that may influence a person's personality. These factors may also reveal a person's personality. Attitudes, emotions, will, values, and behaviors are examples of these components.

When it comes to someone's demeanor, it's generally called a sign of their personality. The attitude of a human when confronted with something he encounters normally reflects his character; nevertheless, not all of the attitude displayed reflects his character; there are some potential factors that cause him to reveal his attitude. Strong emotions are associated with emotion. In a case where amnesia is experienced, emotion is a complex symptom that is followed by its impact on awareness, actions, and is often a physiological mechanism.

Trust and belief are human cognitive components of sociopsychological influences. Belief that something is real or false based on suggestion, knowledge, knowledge, and institutions are critical in the development of human character and morality.

Habits and willpower are two different things. Habit is a type of action that is constant, occurs naturally, and is not valued. A habit is a long-term pattern or a predictable response that is replicated often. The aspect of the character must be created. However, we would continue to believe that schooling, as a change agent, must be able to transform good students' character into good character and turn noble characters into even better characters.

\section{Characteristics of Character Education}

Any behavior led by normative principles is emphasized in character education. Present standards are respected and followed by students. The presence of coherence or the development of self-confidence and bravery, such that students become firm individuals who are not easily influenced and who are not fearful of taking chances when confronted with new situations. The nature of sovereignty, through which students respect and practice beyond laws in order to develop principles for themselves. Students would be able to make independent choices without being swayed by outside pressure in this manner. Persistence and obedience are students' aversion to realizing what they perceive to be healthy. And appreciation for the commitment chosen is based on loyalty.

Many adolescents are dissatisfied with their schoolteachers' classes. Complaints may include a vast amount of tasks, boring learning procedures, or exercises that are too difficult or vague.

Humans must preserve themselves by upholding physical and moral purity, constantly growing intelligence, cultivating self-discipline, and attempting to perform praiseworthy acts while preventing despicable behavior in order to develop a virtuous character. If anyone really wishes to develop character, they must do it in various facets of their lives.

Character curriculum may be implemented in a variety of forms, including the incorporation of special education subjects into each topic or a holistic solution that incorporates accessible educational spaces into the broader dynamics of school education. Any topic that needs to be created, rendered clear, and connected to daily contexts may include character education. As a result, there is already a lot of need for foreign language learning to contribute to the development of character centered on societal ethical norms. Foreign language research should be organized in such a manner that the different principles present in foreign language debate can be investigated and discussed. Character education can take several forms and approaches. First, a comprehensive approach to character instruction (The Holistic Approach). Character teaching is incorporated into all facets of school life using this method. Second, Year II, Number 1 (October 2012), Character Education Journal Smorgasbord technique, in which instructors may engage in a series of exercises to help students develop character. Building a 
compassionate society is one of these practices, as are teaching principles through the curriculum, class dialogue, and service learning.

\section{The Role of Character Education for Adolescents}

The importance of character education for youth cannot be overstated. It is especially easy for teenagers to slip into promiscuity while they are in a less positive setting. Here are some of the positions that character education can play in the lives of adolescents.

This education will help students boost their academic performance. Any children are unable to develop powerful personalities in other settings. Individuals who love and accept others and who will exist in a pluralistic community can be created. As a means of addressing the underlying causes of moral-social issues such as dishonesty, immodesty, crime, a lack of work ethic, and so on. Is the most effective way to mold an individual's behaviour before joining the workforce or industry. As a means of instilling cultural ideals that are integral to civilization's function

Character education aims to build students' future conscience, spirit, and affective as individuals with traditional principles and national character, among other things (Arthur, 2003; Baharun, 2017; Lapsley \& Narvaez, 2007; Hasib et al., 2017; Abbas, 2019). Developing praiseworthy pupil conduct patterns that are consistent with the nation's core ideals and faith practices. Instill in students a sense of leadership and duty as the nation's future citizens. Students' capacity to become autonomous, artistic, and nationalistic is being created. Creating a safe, fair, imaginative, and fun atmosphere in the school environment.

Formation and growth of talent such that students can maximize their ability to think critically, have a clear conscience, and function with integrity. Consolidation and enhancement Improve and reinforce the positions of people, households, school units, societies, and governments in carrying out their duties and contributing to the development of organizations, and society as a whole. Character education should be used to help citizens select and sort their own national identity, as well as weed out cultures from other countries that are not in line with the virtuous ideals of their own nation's character and culture.

\section{The Importance of Character Education for Youth}

Character education is thought to be beneficial since it helps to balance cognitive abilities. Some of the realities we often hear are that a wealthy businessman is not charitable, that a leader is always unconcerned with his hungry neighbours, and that an instructor is unconcerned about seeing street children who do not have access to an education. Much of this points to a lack of coordination between cognitive and character education.

Lack of character instruction can result in a moral dilemma, which will contribute to negative actions in culture, such as promiscuity, illicit substance addiction, fraud, and aggression against children, among other things.

Religious Character Values are one of the five major character values that come from Pancasila. The implementation of religious character values in the everyday life of culture can be seen in many respects, like. Nationalist character principles are a way of thought, speaking, and behaving that demonstrates commitment, care, and appreciation for the nation's language, climate, social, cultural, and political institutions. The incorporation of nationalist character ideals in daily life can be used in a variety of forms (Alexander, 2001). The importance of character honesty is the value that becomes the foundation for any individual's actions such that he or she can be believed with his or her speech and acts and is dedicated to spiritual and human principles.

The importance of honesty as a character trait can be seen in a variety of forms of people's everyday lives. Character principles that are independent of other people's beliefs and practices 
are known as independent character values. In other terms, an autonomous person can use his or her intellect, resources, and time to achieve his or her goals. Character Values of Mutual Cooperation; Mutual cooperation values are actions and actions that uphold the principle of cooperation and work together to solve problems.

\section{Factors Influencing Character Education}

We must first understand what influences affect a person's character before deciding the methods used to provide character education. Character education's effectiveness or failure is influenced by a number of factors. The Instinct Factor is used in this (Instinct). The mentality and character that has been established since birth is referred to as instinct. Personalized (Habit), A pattern of action that is replicated again and again before it becomes habitual. The moral and physical features of an infant are partially a result of the behaviors and characteristics of their parents. Anything about a person's environment (milieu), including rituals, associations, school environments, towns, communities, and so on, can have a direct or indirect impact on his or her character. Environmental considerations play a significant role in character education and improvements in student attitudes as a part of the character education phase are heavily influenced by these factors. In other terms, the physical and cultural climate of the classroom, school administration, curriculum, educators, and instructional practices are also part of the creation and environmental culture.

\section{Optimization of Character Education towards Youth-Free Association}

In the current environment, character education is critical for solving the spiritual crisis that is afflicting our society. Promiscuity is on the rise, as is brutality against children and youth, criminality against peers, juvenile robbery, gambling activities, substance addiction, pornography, and the misuse of other people's goods, many of which have turned into societal issues that have yet to be solved. Fully settled Demoralization arises as a result of the learning experience, which teaches moral and character instruction in a text-based manner and does not allow students to react to and confront conflicting situations in their lives. Furthermore, religious instruction has long been regarded as an important means of instilling in students a virtuous character. In fact, all it is doing is teaching the fundamentals of faith. In reality, his position as a media for guiding his students to recognize and follow their religious teachings is dwindling. This may be one of the explanations why, in the sense of formal education in schools / madrasas, education in Indonesia focuses mostly on intellectual or cognitive learning alone, whereas soft skills or non-academic dimensions as the key element of moral education are not considered. In particular, as has been the case in our clinical experience, the achievement of student learning outcomes must be measured not just in cognitive and psychomotor realms, but also in affective outcomes.

Moral education plays three roles in forming virtuous morality or character in students: first, moral knowing, which is the application of moral principles by spiritual lessons such as morals to God, ourselves, and kin, and so on. By HW practices, congregational prayers, the habit of reading the Koran in the morning until the first hour of lessons starts, among other means, all religious emotions encourage an outlook or need for spiritual principles. The third is moral doing, which refers to the performance of instilling certain moral principles in everyday life in the hopes that children would be able to incorporate the moral values learned in lessons and school activities.

Aging, war, truancy, dating, and other delinquencies are common. Since certain students are unable to differentiate between what is correct and what is incorrect, they just mimic their peers. Preventive efforts by promoting religious behaviors (kissing hands with instructors, saying greetings while interacting, etc.), fostering civic obligation attitudes through $\mathrm{HW}$ practices, and practice services as learning apps are also part of moral education's function in addressing delinquency. The second type of intervention involves school-based programs. Students may

Copyright ( 2021, Journal of Asian Multicultural Research for Educational Study, Under the license CC BY-SA 4.0 
develop or embed a religious mentality as a result of this habit, and stay away from negative activities like these delinquencies.

\section{Conclusion}

The goal of improving teenage character education is to wait for early behaviors, emotions, and psychology toward teenagers before slipping into promiscuity. Promiscuity is on the rise in this generation because teens' personalities, egos, and emotions are all undergoing drastic changes. This is often affected by a less welcoming atmosphere, which makes it easier for teens to slip into promiscuity, which may be detrimental to their future. A child would be able to easily control impulses and use logic in taking action or making choices in their life if character teaching is implemented thoroughly and consistently.

\section{References}

Abbas, E. W. (2019). Building Nation Character through Education: Proceeding International Seminar on Character Education.

Alexander, J. C. (2001). Theorizing the "modes of incorporation": Assimilation, hyphenation, and multiculturalism as varieties of civil participation. Sociological theory, 19(3), 237249.

Arthur, J. (2003). Education with character: The moral economy of schooling. Psychology Press.

Baharun, H. (2017). Total Moral Quality: A New Approach for Character Education in Pesantren. Ulumuna, 21(1), 57-80.

Dodds, D. M. (2016). The effects of character education on social-emotional behavior.

Hasib, M., Nahruddin, Z., Tahir, M. M., Handam, M., Akbar, M. F., \& Nurdiansyah, W. (2017, November). Local Wisdom and Character Education in Youth Organizations--A Case Study of South Sulawesi Province, Indonesia. In International Conference on Administrative Science (ICAS 2017) (pp. 157-162). Atlantis Press.

Jensen, E. (2009). Teaching with poverty in mind: What being poor does to kids' brains and what schools can do about it. AScD.

Lapsley, D. K., \& Narvaez, D. (2007). Character education. Handbook of child psychology, 4.

Richardson, R. C., Tolson, H., Huang, T. Y., \& Lee, Y. H. (2009). Character education: Lessons for teaching social and emotional competence. Children \& Schools, 31(2), 71-78.

Short, J. F. (1957). Differential association and delinquency. Social Problems, 4(3), 233-239.

Vaccarezza, M. S., \& Niccoli, A. (2019). The dark side of the exceptional: On moral exemplars, character education, and negative emotions. Journal of Moral Education, 48(3), 332345.

Wagner, T. (2010). The global achievement gap: Why even our best schools don't teach the new survival skills our children need-and what we can do about it. ReadHowYouWant. com. 